\title{
Moving beyond Limitations: Designing the Helpdys App for Children with Dyslexia in Rural Areas
}

\author{
Andres Larco ${ }^{1, *(\mathbb{D})}$, Jorge Carrillo ${ }^{1}$, Nelson Chicaiza ${ }^{1}$, Cesar Yanez ${ }^{1}\left(\mathbb{D}\right.$ and Sergio Luján-Mora ${ }^{2}(\mathbb{D}$ \\ 1 Departamento de Informática y Ciencias de la Computación, Escuela Politécnica Nacional, \\ Quito 17-01-2759, Ecuador; jorge.carrillo@epn.edu.ec (J.C.); nelson.chicaiza@epn.edu.ec (N.C.); \\ cesaryanezv@outlook.com (C.Y.) \\ 2 Department of Software and Computing Systems, University of Alicante, 03690 Alicante, Spain; \\ sergio.lujan@ua.es \\ * Correspondence: andres.larco@epn.edu.ec; Tel.: +593-998-981-007
}

check for

updates

Citation: Larco, A.; Carrillo, J.; Chicaiza, N.; Yanez, C.; Luján-Mora, S. Moving beyond Limitations: Designing the Helpdys App for Children with Dyslexia in Rural Areas. Sustainability 2021, 13, 7081. https://doi.org/10.3390/su13137081

Academic Editors: Maria Kett,

Catherine Holloway and

Victoria Austin

Received: 25 April 2021

Accepted: 25 May 2021

Published: 24 June 2021

Publisher's Note: MDPI stays neutral with regard to jurisdictional claims in published maps and institutional affiliations.

Copyright: (C) 2021 by the authors Licensee MDPI, Basel, Switzerland. This article is an open access article distributed under the terms and conditions of the Creative Commons Attribution (CC BY) license (https:/ / creativecommons.org/licenses/by/ $4.0 /)$.

\begin{abstract}
Dyslexia is a relatively common language disorder which is generally ignored in rural communities. It hinders children's learning processes and, in some cases, is the cause of dropouts or violence in schools. The present work strives to create a web and mobile app as a preliminary step towards the diagnosis and treatment of dyslexic children. Apps providing didactic educational games and activities improve literacy skills for students with reading disabilities. The current work incorporates user experience and prototyping to fulfill app requirements. The authors evaluated the apps with the Mobile App Rating Scale (MARS) tool to assess engagement, functionality, aesthetics, and information. The app's improvements were immediately implemented and tested in the "Escuela Linea Equinoccial" (Ecuador) school, proving its utility for future use in the education system. The app can be a valuable tool for children with dyslexia to progress successfully through school, raising their self-confidence and, thereby, helping them reach their full potential as adults able to make a positive contribution to society.
\end{abstract}

Keywords: dyslexia; inclusive education; mobile apps; rural area; sustainable apps; web apps

\section{Introduction}

Special educational needs (SEN) [1,2] which are not associated with physical disabilities are an unknown topic to many [3,4]. For that reason, some students cannot overcome their learning obstacles, which in many cases cause violence, bullying, and school dropouts [5]. Education, hand in hand with information and communication technologies (ICT), brings tools and innovative alternatives which improve students' daily lives. ICT also includes support for learning difficulties related to dyslexia, mainly identified in the early years of school education [6].

The Diagnostic and Statistical Manual of Mental Disorders (DSM-5) [7] considers a specific learning disability (SLD) to be a type of neurodevelopmental disorder which impedes learning or the use of specific academic skills that are the foundational for other academic learning. Early signs may appear in the preschool years, but they are only diagnosed reliably after the start of formal education. SLD is understood to be a cross-cultural and chronic condition that typically persists into adulthood. Dyslexia, one of the most common SLD manifestations, implies difficulties in learning [8].

Dyslexia is a term used to refer to a pattern of learning difficulties characterized by problems with accurate or fluent word recognition, poor decoding, and poor spelling abilities [7]. In addition to the aforementioned problems, dyslexia can also be accompanied by difficulties in reading comprehension or math reasoning.

According to the International Dyslexia Association [9], dyslexia presents difficulties that typically result from a deficit in the phonological component of language that is often unexpected concerning other cognitive abilities and the provision of effective classroom 
instruction. Secondary consequences may include reading comprehension problems and reduced reading experience, impeding the growth of vocabulary and background knowledge [10]. In this context, the studies concerning this area recognize that dyslexia is a high-impact issue which inhibits the teaching-learning processes [11].

A recent review [12] about dyslexia around the world provides a global picture of this type of SLD. Worldwide, numerous institutions and schools offer support for parents, teachers, and people with dyslexia. Looking at all languages, there is no single cause for dyslexia, and several aspects should be considered. An additional factor to consider is that diagnostic precision is likewise influenced by poverty, limitations, lack of opportunity, and language variants. Furthermore, there are still countries where students are not identified and do not obtain evidence-based early interventions. Hence, both parents and teachers require information concerning methodical, specific reading and spelling guidelines. Although many countries have taken positive action to enhance the education, learning, and overall lives of people with dyslexia, in some countries, dyslexia is still not acknowledged or well understood, and people with these special reading needs are stigmatized.

According to Mather et al. [12], in Ibero-America, only Brazil, Costa Rica, and Spain are International Dyslexia Association (IDA) global partners. Additionally, Brazil, Costa Rica, and Puerto Rico have schools and centers that serve students with dyslexia. Finally, Costa Rica and Puerto Rico have organizations with a social media presence.

In Ecuador, the Ministry of Education has not yet carried out a study into dyslexia. For this reason, there are no national or provincial statistics. However, there has been a study of the cases of dyslexia in Quito and Cuenca. According to Mendez's [13] study, carried out in the urban and suburban areas of the Metropolitan District of Quito (Ecuador), the causes of failing and repeating the school year were: finances, $33 \%$; health, $16 \%$; and learning difficulties, $51 \%$. Of the $51 \%$ with learning difficulties, $26 \%$ corresponded to dyslexia.

The study by Velez et al. [14] reviews the incidence of dyslexia in 207 primary school students, from 8 to 13 years of age, who attend public and private institutions in the city of Cuenca (Ecuador). It states that $26.57 \%$ of students presented signs of dyslexia, of whom $36 \%$ had superficial dyslexia, 33\% phonological dyslexia, and 31\% mixed dyslexia. It is for this reason that we present our study to improve the possibilities for students with dyslexia with the applied use of ICT.

There is a steady growth of tablet and smartphone apps that provide help to people with dyslexia. Apps aimed toward didactic educational games and activities improve literacy skills for students with reading disabilities [15].

Smartphones may be an affordable part of the solution for vulnerable groups with SEN. For that reason, the current work explains the design and use of web and mobile apps with the purpose of helping children with dyslexia. Specialized professionals require technology to help children with dyslexia in their academic development. Technology has proven essential, especially in crisis, pandemic, or emergency scenarios, such as the current worldwide situation due to COVID-19 [16]. Technology performs a vital role in the attention continuity required by dyslexic children who cannot leave their homes due to their vulnerability and the risk of contagion.

We address the following research questions in this work:

RQ1. How can web and mobile apps support the learning process of children with dyslexia?

RQ2. How can an app for supporting the learning process of children with dyslexia be developed?

RQ3. What is the acceptance of the app by end users?

Finally, the previously presented issues focus on selecting tools that can improve the lives of people with dyslexia. The current work presents web and mobile apps, including didactic educational tools for dyslexic children from 7 to 10 years of age. Additionally, the authors aim to offer an important contribution to the improvement of the treatment of 
dyslexic children with the use of interactive games for reading, writing, and math skills, encouraging these children to use ICT to overcome their learning obstacles.

The structure of the current study is as follows: Section 2 presents the preliminary concepts of dyslexia, its types, and its relationship with technology; Section 3 contains the methods used to conduct the research and development, and it provides technical insights into the app developed; Section 4 presents the main results obtained after the tests of the app; Section 5 contains a discussion of the results obtained; and finally, Section 6 presents the main conclusions and future work.

\section{Preliminary Concepts}

\subsection{Elements of Dyslexia}

Dyslexia is a specific learning difficulty, not a disease. It is related to aspects of reading, spelling, and writing $[17,18]$. Dyslexic students receive the same classroom instruction as other students but fail to profit adequately from this regular classroom instruction [19]. Dyslexia involves a specific deficit in single-word decoding based on a weakness in the phonological aspect of language. Dyslexia has only a secondary impact on reading comprehension, distinguishing it from other types of reading disabilities [20].

Dyslexia can cause other associated specific difficulties; however, these difficulties can present themselves regardless of dyslexia. These difficulties might include:

- Dysgraphia [21] is the condition of impaired letter writing by hand: in other words, disabled handwriting. Impaired handwriting can interfere with learning to spell words in writing and the speed of writing text. Children with dysgraphia may have only impaired handwriting, impaired spelling (without reading problems), or both;

- Dysorthography [22] is a specific disorder of spelling which accompanies dyslexia; the cognitive dysfunction underlying the two disorders is probably common to both. The spelling of words is highly deficient, a direct consequence of the phonological disorder in dyslexic children;

- Dyscalculia [23] is a condition that affects the ability to acquire arithmetical skills. People with this condition may have difficulty understanding simple number concepts and have problems learning number facts and procedures. Even if they produce a correct answer or use a proper method, they may do so mechanically and without confidence.

Dyslexia occurs on a continuum from mild to severe, and no two people with dyslexia are alike [24]. There is no cure for dyslexia, since it is neurobiological; however, with appropriate evidence-based instruction aimed towards their learning needs, people with dyslexia can learn to read, spell, and write.

A student with dyslexia will have difficulty with developing functional brain-based networks for single-word reading. Individuals with dyslexia can often access higher-level language skills to support their reading of a connected text. This ability to "compensate" may mask their underlying difficulties with single-word reading (decoding). According to Snowling [25], dyslexia can be caused by hereditary factors, brain processes, and phonological awareness.

Research has indicated that therapists should be aware of automatically assuming that the language processing difficulties associated with dyslexia are irreversible, but this is not the case. With appropriate support, dyslexic students can display development in their skills [19].

Dyslexia has been reported in approximately 1 in 10 people, threatening at least 700 million children and adults worldwide with life-long illiteracy and social exclusion [5]. Dyslexic students face the disadvantage of having failed in early life. The long-term effects on young adults include failure at school, depression, and an increased risk of suicide, delinquency, and prison sentences [26].

Indeed, the human cost of dyslexia [27] details the overall costs to society that result when illiteracy secondary to dyslexia is ignored. They include social costs, unemployment, consequent mental health issues, and remedial programs and expenses incurred due to 
antisocial behavior, such as drug abuse, teenage pregnancy, and, most significant of all, criminal involvement.

According to the World Health Organization (WHO) [28], around 15\% of the world population is affected by a disability, harming their personal, academic, and social development. The most affected are families live in rural areas [29]. Technology provides tools on the Internet which have significantly changed the lives of dyslexic children and families. For years, the only way to treat children with dyslexia was to improve their literacy through instruction and teaching based on evidence. Now, cutting-edge technology and adequate tools reduce learning difficulties. One strength of technology is independence. For example, using text-to-speech apps reduces children's reliance on teachers or parents to help them read. In this way, with prediction and word dictation, children can improve their orthography. Another benefit of technology [30] is that the new devices are portable.

Technology aids many aspects of children's development, such as improving their selfconfidence, optimizing their education, and overcoming reading difficulties by focusing on their strengths [30]. Through specific adaptations, people with disabilities are included in certain workplaces from which they were previously excluded. Technology has become an essential factor of social inclusion, which improves people's earning potential. The growing use of technology allows for the normalizing of their routines in an entirely digital environment [31].

There are several approaches across the world to support the conditions of dyslexia, such as reading problems. For example, GraphoGame (Grapho Group Oy, Helsinki, Finland) [32] has been created to help children with reading difficulties. This app has been used in Zambia, Namibia, Kenya, Tanzania, India, and Finland [33]. GraphoGame and GraphoLearn (University of Jyväskylä and Niilo Mäki Institute, Jyväskylä, Finland) focus on teachers' and parents' support of children in their reading learning process [34].

\subsection{Software and Sustainability}

Technology is essential for organizations to overcome inherent educational issues. As Stroustrup [35] observed, our current civilization depends highly on software. Without understanding software, there is a risk of missing out on many opportunities to attain the most interesting, profitable, and socially useful technical fields of work.

As software sustainability is becoming a must-have for organizations, many are aware that developing solutions which consider sustainability is now recognized as a competitive business advantage. Thus, the software is an advantage for the attainment of smart cities and buildings. Sustainable software is closely related to human, economic, and environmental factors [36]. As Penzestadler et al. [37] explained, sustainability has recently received recognition as a quality objective for software.

Mobile apps can stimulate students in the learning process and provide a more flexible and adaptable educational approach. As 4.66 billion people are connected to the Internet [38], many when using mobile phones, providing useful content in mobile apps for educational purposes is significant. Mobile apps [39] are only valuable for education when individuals understand how they can apply the information and how they can alter their behavior. Awareness of these motivations helps in the design of more effective apps.

\section{Method}

The current research uses a method based on design science research (DSR), proposed by Hevner et al. [40]. This framework is active in technology, partaking in creating technical artifacts which affect people and organizations. It focuses on solving problems but usually only considers a simplified view of the people and the organizational environment it has to work with. The DSR has elements for comparison with competing products, the design of artifacts, their formal specifications, and an evaluation of their effectiveness.

The purpose is to reproduce prototypes and user-oriented evaluations [41], taking as a reference the guidelines of DSR for the recent work [42]. The DSR [43] process includes six steps: 
1. Problem identification and motivation;

2. Objectives of the solution;

3. Research into the existing apps for people with dyslexia;

4. Design and development;

5. Demonstration;

6. Evaluation.

\subsection{Problem Identification and Motivation}

Often ignored by rural communities, dyslexia is a language disorder which damages children's learning processes; in some cases, this disorder is the cause of violence and school dropouts [44]. Currently, rural zone teachers in Ecuador must conduct adjustments to their sessions to help children; however, they do not have digital tools to maintain their learning. The current work is an initial approach that contributes to the diagnosis and treatment of dyslexic children in the rural communities of Calacali, Ecuador.

\subsection{Objectives of the Solution}

The objective is to create web and mobile apps which allow users access to learning resources for dyslexia treatment. These apps are intended to promote the use of new technologies for learning for children from 7 to 10 years old.

\subsection{Research into Existing Apps for People with Dyslexia}

A search of existing apps was carried out to research the type of activities, games, and information to compile a beneficial and easy-to-use app for children with dyslexia. A search was done with the keywords "dyslexia apps"; the same search was then conducted in the Spanish language: "dislexia aplicaciones". In both cases, apps were found in Google Play and the App Store, as shown in the compendium in Table 1.

Table 1. Apps for dyslexia in Google Play and App Store.

\begin{tabular}{|c|c|c|c|}
\hline ID & Name & Summary & Features \\
\hline 1 & Voice dream reader & $\begin{array}{l}\text { Objective, to help people with } \\
\text { dyslexia. Read with a synthesized } \\
\text { voice, the texts that appear on the } \\
\text { screen: from PDF, Word, e-books, } \\
\text { articles, web pages. }\end{array}$ & $\begin{array}{l}\text { Skill: Reading. } \\
\text { Grade level: All levels. } \\
\text { Language: English, Spanish, French, German, Italian. } \\
\text { Price: \$9.99 Android, \$14.99 iOS. } \\
\text { Device: Android and iOS. }\end{array}$ \\
\hline 2 & Letters and $\mathrm{Me}$ & $\begin{array}{l}\text { An interactive story explains what } \\
\text { dyslexia is through the feelings of } \\
\text { a girl who, no matter how hard } \\
\text { she tries, does not learn letters } \\
\text { like her peers. }\end{array}$ & $\begin{array}{l}\text { Skill: Reading. } \\
\text { Grade level: Primary. } \\
\text { Language: Spanish, Catalán, English, Italian, Galego. } \\
\text { Price: \$3.99 Android, \$2.40 iOS. } \\
\text { Device: Android and iOS. }\end{array}$ \\
\hline 3 & Piruletras (Dyseggxia) & $\begin{array}{l}\text { Objective, to improve the reading } \\
\text { and writing of dyslexic students } \\
\text { with fun activities. }\end{array}$ & $\begin{array}{l}\text { Skill: Dyslexia. } \\
\text { Grade level: Primary and secondary. } \\
\text { Language: Spanish. } \\
\text { Price: Free and Paid } \$ 0.99 \text {. } \\
\text { Device: iOS }\end{array}$ \\
\hline 4 & Dytective para dislexia & $\begin{array}{l}\text { It is a tool which improves skills } \\
\text { related to reading and writing in a } \\
\text { fun way while playing. }\end{array}$ & $\begin{array}{l}\text { Skill: Dyslexia. } \\
\text { Grade level: Primary and secondary. } \\
\text { Language: Spanish. } \\
\text { Price: Free. } \\
\text { Device: Android and iOS. }\end{array}$ \\
\hline 5 & Deslixate & $\begin{array}{l}\text { It is a support tool for specialists } \\
\text { in areas oriented to learning, with } \\
\text { children with dyslexia. }\end{array}$ & $\begin{array}{l}\text { Skill: Learning disabilities. } \\
\text { Grade level: All. } \\
\text { Language: Spanish. } \\
\text { Price: Free. } \\
\text { Device: Android. }\end{array}$ \\
\hline
\end{tabular}


Table 1. Cont.

\begin{tabular}{|c|c|c|c|}
\hline ID & Name & Summary & Features \\
\hline 6 & Galexia & $\begin{array}{l}\text { Educational games help reading } \\
\text { fluency and speech difficulties, } \\
\text { using a variety of activities and } \\
\text { mini games. }\end{array}$ & $\begin{array}{l}\text { Skill: Reading fluency. } \\
\text { Grade level: Primary and secondary. } \\
\text { Language: Spanish. } \\
\text { Price: Free. } \\
\text { Device: Android. }\end{array}$ \\
\hline 7 & $\begin{array}{l}\text { Dislexia: ejercicios } \\
\text { practicos (Dyslexia: } \\
\text { practical exercises) }\end{array}$ & $\begin{array}{l}\text { Objective, to help people with } \\
\text { dyslexia, covering the phonetic, } \\
\text { phonological, morphological, and } \\
\text { syntactic language levels. }\end{array}$ & $\begin{array}{l}\text { Skill: Dyslexia. } \\
\text { Grade level: All. } \\
\text { Language: Spanish. } \\
\text { Price: } \$ 3.99 . \\
\text { Device: Android. }\end{array}$ \\
\hline 8 & Dislexis & $\begin{array}{l}\text { It has two modules: the first, a } \\
\text { diagnostic test, and the second, a } \\
\text { test mode, an interactive game. }\end{array}$ & $\begin{array}{l}\text { Skill: Dyslexia. } \\
\text { Grade level: Primary and secondary. } \\
\text { Language: Spanish. } \\
\text { Price: Free. } \\
\text { Device: Android. }\end{array}$ \\
\hline 9 & $\begin{array}{c}\text { Dislexia prueba y } \\
\text { consejos (Dyslexia test } \\
\text { and tips) }\end{array}$ & $\begin{array}{l}\text { A test for teachers or other people } \\
\text { to use when someone is suspected } \\
\text { of being dyslexic. }\end{array}$ & $\begin{array}{l}\text { Skill: Dyslexia. } \\
\text { Grade level: All. } \\
\text { Language: English. } \\
\text { Price: \$3.53 Android, \$3.49 iOS. } \\
\text { Device: Android and iOS. }\end{array}$ \\
\hline 10 & Crazy cursive letters & $\begin{array}{l}\text { Objective, to practice cursive } \\
\text { writing, forming letters and } \\
\text { words in a fun way. }\end{array}$ & $\begin{array}{l}\text { Skill: Reading and writing. } \\
\text { Grade level: Preschool. } \\
\text { Language: English. } \\
\text { Price: } \$ 3.99 \text { Android, } \$ 4.99 \text { iOS. } \\
\text { Device: Android and iOS. }\end{array}$ \\
\hline 11 & Montessori words & $\begin{array}{l}\text { Objective, to help children } \\
\text { develop their literacy by building } \\
\text { words using images, sounds, and } \\
\text { phonetics. }\end{array}$ & $\begin{array}{l}\text { Skill: Reading and writing. } \\
\text { Grade level: Children up to } 8 \text { years. } \\
\text { Language: English. } \\
\text { Price: } \$ 3.99 \text { Android, } \$ 2.99 \text { iOS. } \\
\text { Device: Android and iOS. }\end{array}$ \\
\hline 12 & $\begin{array}{c}\text { Cursive writing } \\
\text { wizard }\end{array}$ & $\begin{array}{l}\text { Objective, to help children learn } \\
\text { how to track custom letters, } \\
\text { numbers, and words using a fun } \\
\text { system. }\end{array}$ & $\begin{array}{l}\text { Skill: Reading and writing. } \\
\text { Grade level: Preschool. } \\
\text { Language: English. } \\
\text { Price: \$3.99 Android, \$4.99 iOS. } \\
\text { Device: Android and iOS. }\end{array}$ \\
\hline 13 & Dyslexia quest & $\begin{array}{l}\text { Objective, to diagnose dyslexia } \\
\text { while the user plays Yeti games, } \\
\text { which assess visual and auditory } \\
\text { memory, phonology, processing } \\
\text { speed. }\end{array}$ & $\begin{array}{l}\text { Skill: Reading. } \\
\text { Grade level: Primary. } \\
\text { Language: English. } \\
\text { Price: } \$ 1.99 . \\
\text { Device: iOS. }\end{array}$ \\
\hline 14 & Eye games dyslexia & $\begin{array}{l}\text { Objective, to help the brain in a } \\
\text { fun way to make direct } \\
\text { connections. }\end{array}$ & $\begin{array}{l}\text { Skill: Reading. } \\
\text { Grade level: Primary. } \\
\text { Language: English. } \\
\text { Price: Free. } \\
\text { Device: Android. }\end{array}$ \\
\hline
\end{tabular}

All the apps were tested once the respective search was carried out; as is common with most children, the most effective way to help dyslexic children is through games [45]. Particularly useful are the games [46] where the user is required to complete the words using the vowels or consonants that cause difficulties. In order to develop the web and mobile apps proposed in the current work, the following apps were used as the principal examples:

- Letters and Me: for the use of narrated stories; 
- Deslixate: for conducting a prediagnosis evaluation and how to carry out this evaluation by means of a game.

\subsection{Design and Development}

The development of the solution used a spiral model [47]. The reason is the close relation with prototyping. This model helps to perform a rapid development of the versions, more complete in each iteration. The software process is represented as a spiral rather than a sequence of activities, with some backtracking from one activity to another. Each loop in the spiral represents a phase of the software process and combines change avoidance with change tolerance. It assumes that changes result from project risks and includes explicit risk management activities to reduce these risks.

The close relationship between the spiral model and prototypes shows each spiral achieving a deliverable product which helps the user continue improving and refining the interfaces to provide children with an appropriate product for dyslexia treatment. Four prototypes were used during this process, starting with a low-fidelity prototype and ending with an operational prototype.

\subsubsection{User Experience and Prototyping}

User interface (UI) is anything that is designed to be an informational device with which users can interact. UI can include the display screen, keyboard, mouse, and desktop display. User experience (UX) is the art of product design planning, so the interaction with completed products will be as significant as possible. UX includes the interaction with the end user on several IT systems, including the interface, graphics, and design [48].

Both elements are essential for the product and work together, but apart from their professional relationship, their roles themselves are different, referring to the distinct part of the process and the discipline design. The UX has many more elements than the UI, but it also builds on many parts. Understanding this is the most powerful tool for product development [49].

Each level of the user experience (UX) [50] has a close relationship with the creation of prototyping; each level determines the activities:

- The low-fidelity prototype comprises strategy, scope, and structure. It validates the functional requirements and content of the app. This prototype enabled the comprehension of the scope to be confirmed, to obtain a clear idea of the app structure;

- The medium-fidelity prototype focuses on the frame of the app and at this stage, implemented essential elements to fulfill requirements;

- The high-fidelity prototype works with the surface, taking into consideration users' opinions and feedback to improve the design and structure of the apps;

- The operational prototype focuses on the surface, too, but in this phase, refinements were made to the previous prototype, and the changes were then applied in the production of the apps.

In sum, five UX levels can be distinguished, i.e., strategy, scope, structure, skeleton, and surface, as well as four prototypes, i.e., low-fidelity, medium-fidelity, high-fidelity, and operational. Figure 1 shows how the UX levels [50] relate to the prototypes.

\section{Functionality}

The separation of Helpdys into web and mobile app uses the concept of separation of concerns [51], which offers several benefits. Each app can be developed independently and using completely different technologies and programming languages based on its specific requirements. Additionally, it improves reusability and simplifies evaluation.

This app includes three types of users:

1. Guest: a user who can enter without registering and can access the app information;

2. Teacher: a user who needs to be registered to access the app to manage the profiles of their students;

3. Student: a user with and without dyslexia who can access the app information. 


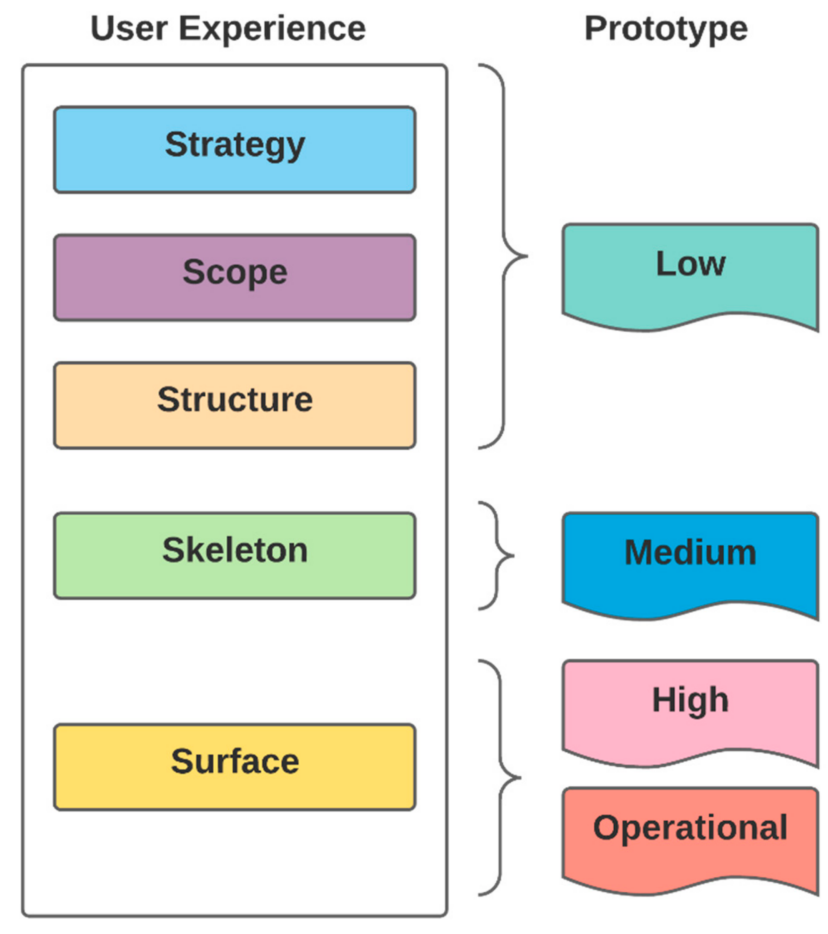

Figure 1. Relation of levels with prototypes developed in the current project.

Collecting Requirements

To collect the requirements, a requirements elicitation was carried out with developers and teachers by means of interviews to obtain information, opinions, and subjective descriptions of the activities. All the functional and nonfunctional requirements were addressed in the project. Afterward, the teachers and the children helped in the creation of the newly tailored requirements of the prototypes. This allowed the users to experiment with the results of their collaboration in the current step and, subsequently, to meet with their approval.

Accessibility

Based on the standards of the Web Content Accessibility Guidelines (WCAG 2.1) [52], the use of colors is a valuable strategy for designing web content. It enhances the aesthetic qualities, usability, and accessibility. In the development of Helpdys, the colors blue, black, and white were used because, according to Bradford [53], these colors are recommended in web accessibility for people with dyslexia [54].

An app should have quality and helpful content, having elements that balance sublimity and functionality; one of these features is the "text font", which enables clear communication. One of the fonts chosen was a sans serif [55]; this font is simple in style and therefore suitable for working with people with dyslexia. Helvetica Neue [56] is an alternative. These fonts work on desktop and mobile screens as well, even with lower resolutions.

\subsubsection{Prototyping}

A prototype is an initial version of a software system used to demonstrate concepts and test designs and to understand more deeply any problems and their solutions. The current solution was implemented in four prototypes (low-fidelity, medium-fidelity, highfidelity, and operational prototype). Each prototype allows the users to check the app's development and provide feedback for each version. At the end of each phase, new ideas and requirements to adapt the software to dyslexic children's needs arise.

The low-fidelity prototype was made in a Lucid chart for a mobile app and Balsamiq for a web app. The main objectives of this prototype were: 
- Identify requirements for the app;

- Establish design concepts;

- Build a navigation model.

Figure 2 shows the two low-fidelity prototypes created: Figure 2a shows the web app's home page prototype; Figure $2 \mathrm{~b}$ shows the mobile app's login page prototype. These two prototypes portray the first teachers' requirements.

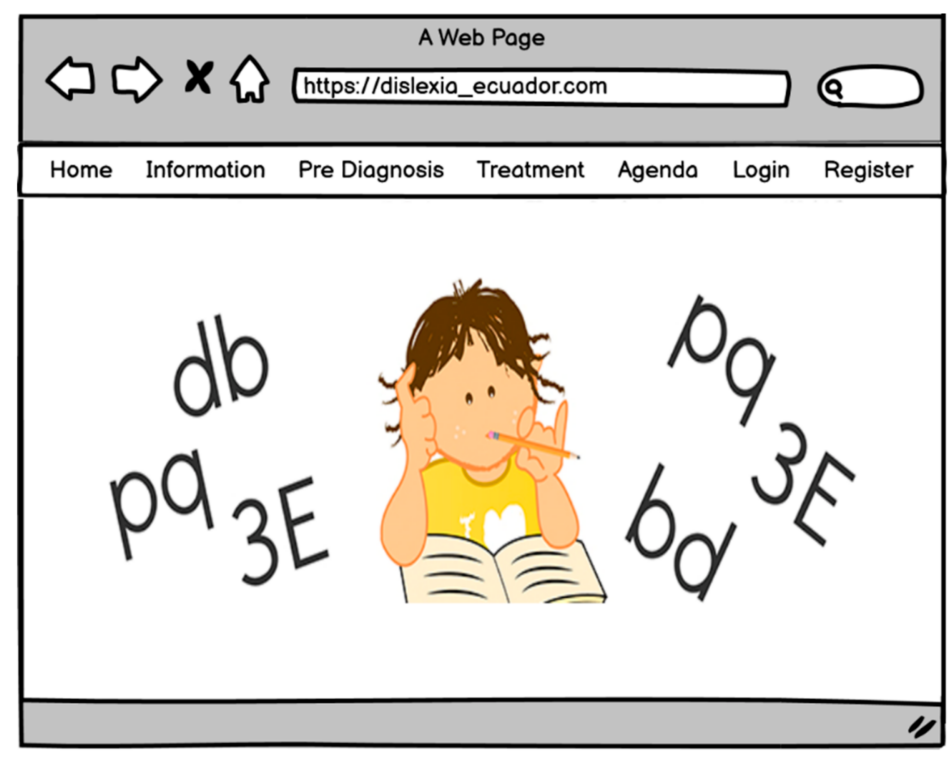

(a)

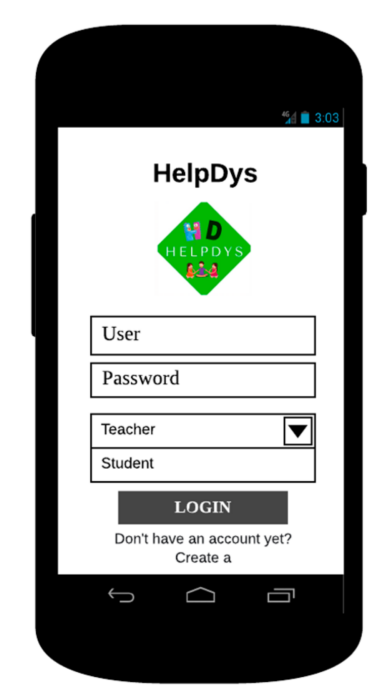

(b)

Figure 2. Low-fidelity prototype: (a) Web home interface; (b) Mobile login interface.

A medium-fidelity prototype defines the frames, sizes, colors, designs, and fonts to create an attractive app for the user and, at the same time, meet the child's needs. The main objectives of this prototype were:

- Fix previous prototype errors;

- Reflect the low-fidelity prototype in the development context;

- Show the functionality of the app;

- Depict the navigation of the app.

HTML and CSS interfaces were created on this prototype using as reference the lowfidelity interfaces. This prototype also implements the first learning resources for children with dyslexia (prediagnosis, tales, and games).

The high-fidelity prototype has a higher interaction between users and developers to obtain feedback and recommendations for enhancing the product. The main objectives of this prototype were:

- Fix medium-fidelity prototype errors;

- Enhance the functionality of the prototype;

- Show the navigability of the prototype;

- Improve the presentation.

The operational prototype: during the implementation of this prototype, mobile and web functionality were fixed based on users' feedback. The final prototype takes all the suggestions and evaluation results and performs a new bug-fixing task. The main objectives of this prototype were:

- Fix high-fidelity prototype errors;

- Apply users' suggestions; 
- Showcase the prototype design with images, colors, fonts, and elements used for the final implementation.

\subsubsection{Interfaces}

This section shows the main interfaces from the Helpdys. Figure 3 shows the games available on Helpdys. The internationally known game, "El ahorcado" (Hangman), is used for word completion based on the image and has a total of 9 attempts. This game allows the children to identify different images and complete the words, stimulating concentration, word recognition, spelling, vocabulary, and photographic memory.

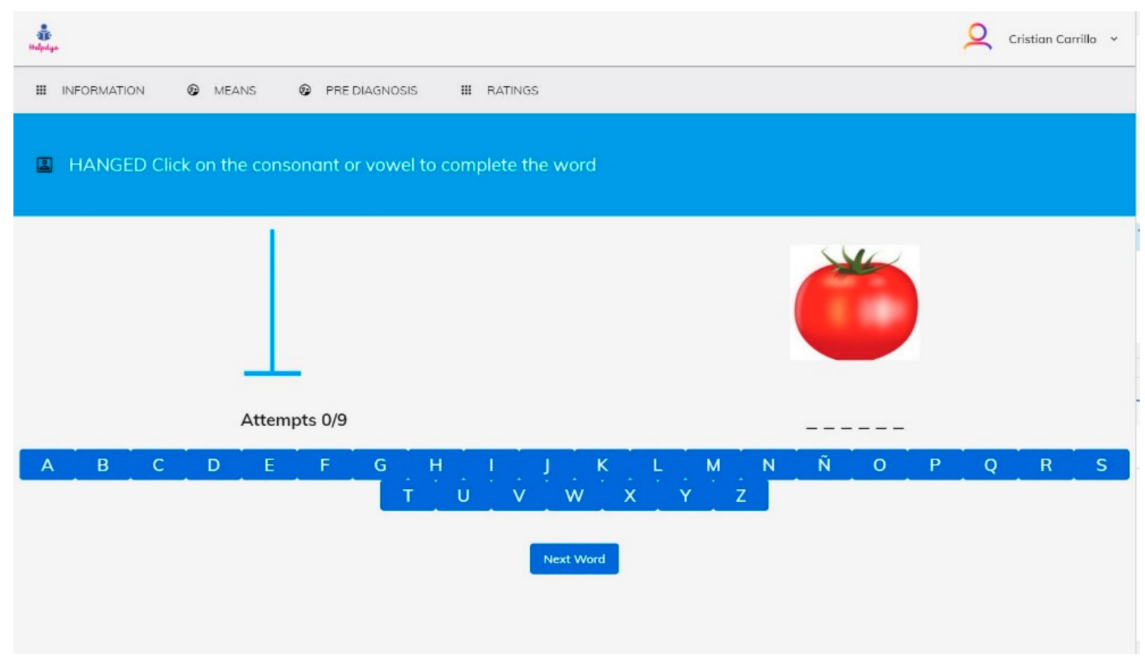

(a)

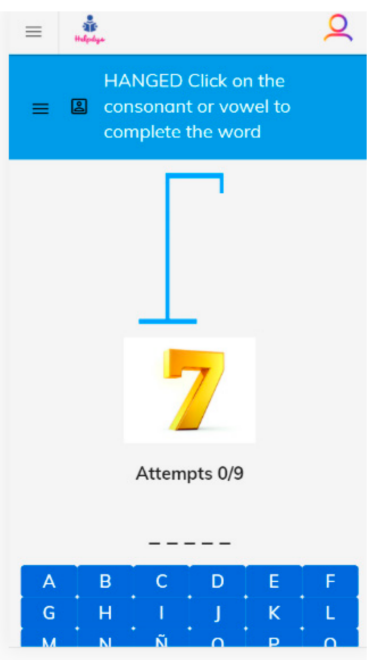

(b)

Figure 3. Operational prototype games: (a) El Ahorcado web interface; (b) El Ahorcado mobile interface.

Figure 4 shows the content of the "Memoria" (Memory) game interface. The game's goal is to find and match pairs, thus stimulating short-term memory and cognitive abilities.

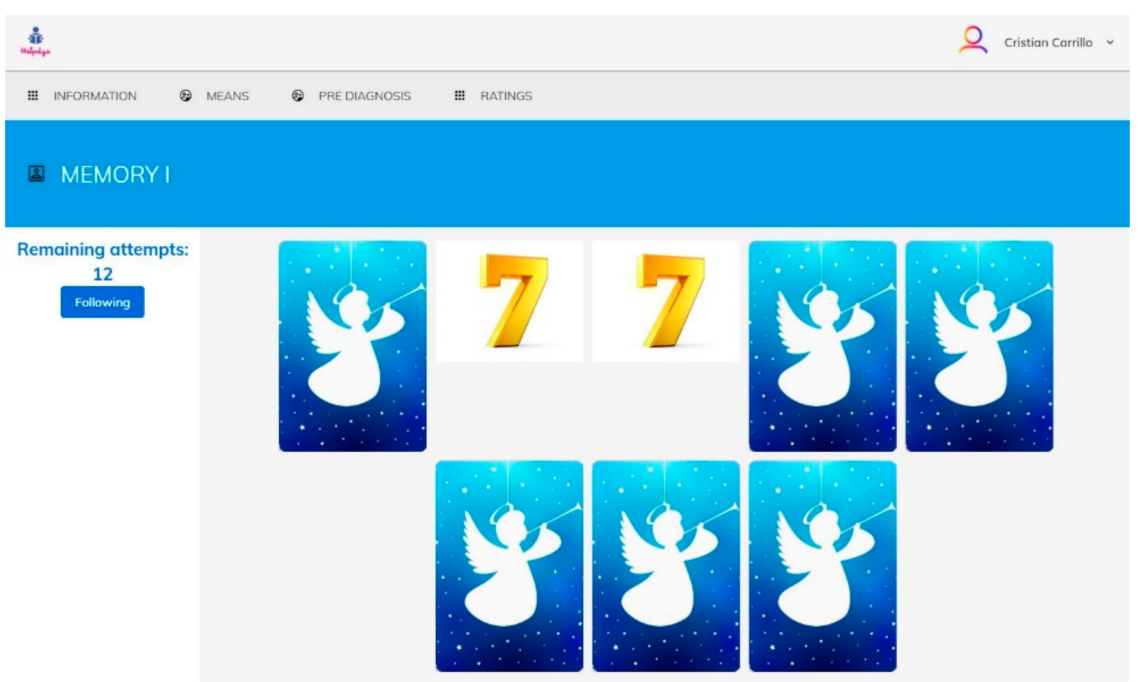

(a)

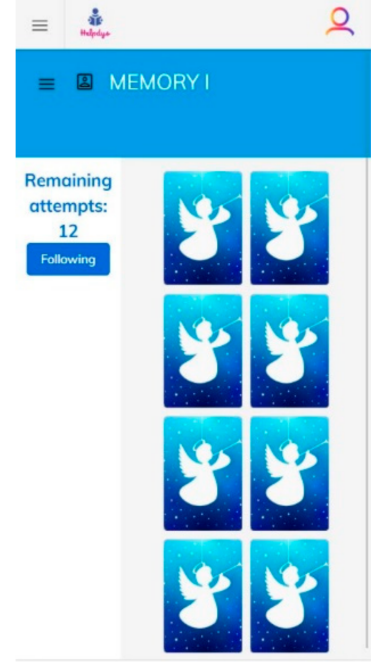

(b)

Figure 4. Operational prototype memory game: (a) Web interface; (b) Mobile interface.

The app also contains supporting material such as videos, tales, and images. The videos interface allows the playback of videos related to dyslexia, such as "famous people with dyslexia", "what is dyslexia?", etc. When choosing any video, it will open in a frame with the video and description. The tales interface displays tales such as "Little Red Riding 
Hood", "Pinocchio", etc. When the children open the tab, the tale appears on the screen. For example, the image interface objective is to show the letters and numbers that children generally confuse, as shown in Figure 5.

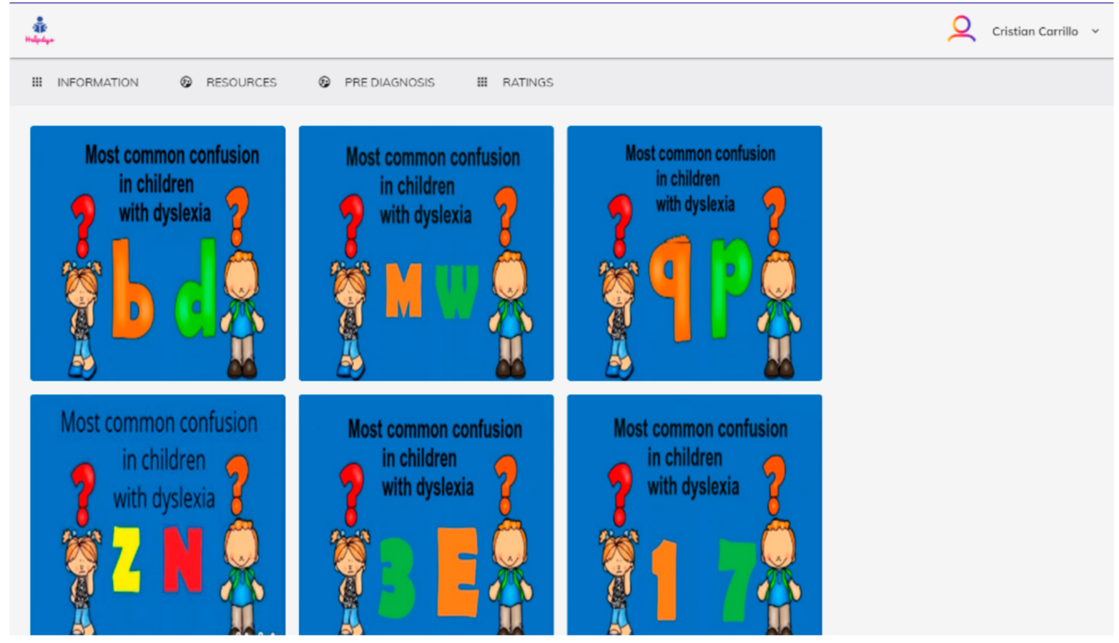

(a)

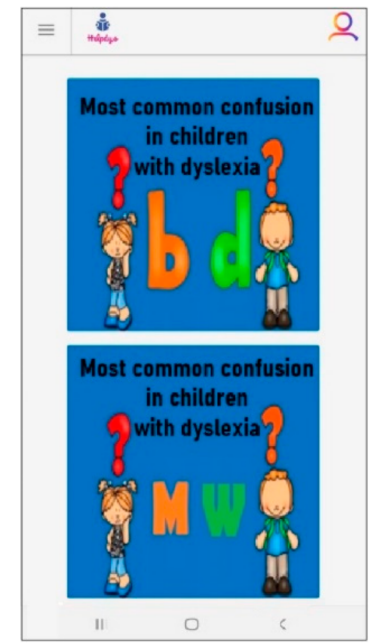

(b)

Figure 5. Operational prototype image: (a) Web interface; (b) Mobile interface.

The student interface is exclusive for teachers; they can create new student profiles on this screen. Teachers have access to their students' records. The agenda objective is to register the data of the meeting sessions for each student. Additionally, the agenda interface provides teachers with a screen that helps them achieve adequate control of the different meetings with students or parents. In this interface, teachers enter meeting data, such as names, topics, times, and dates to hold the respective meetings, and observe them in a weekly or daily calendar view.

The prediagnostic interfaces perform tests [57] using two different games. The first test is to place the vowels to create a word, as shown in Figure 6. The instructions for the game are sent by audio at the interface's initial load. Once the child completes the first test, the score appears, and the user continues the test. The second test consists of selecting the correct word using the same score scale.
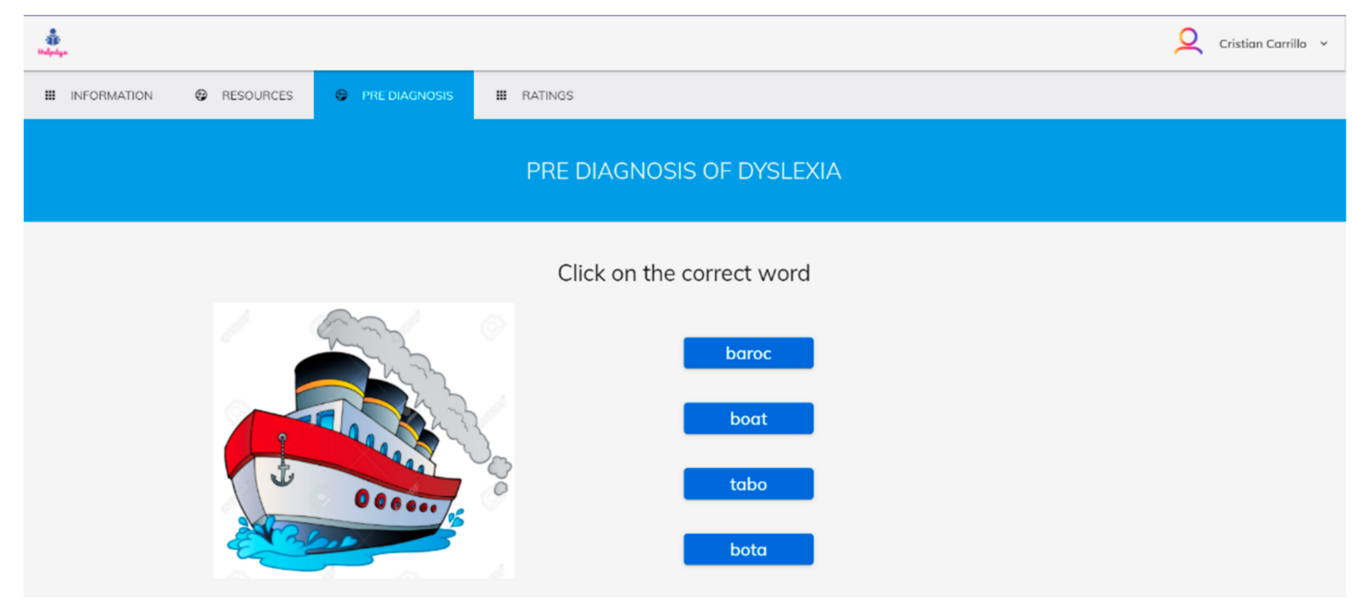

Figure 6. Operational prototype: prediagnosis on mobile interface.

When the test is completed, the results are generated in a PDF; this file will be filled with all the student's information and the interpretation of the results. It is important to mention that the results are referential and do not constitute a medical diagnostic.

Results interpretation is carried out by teacher assessments as follows: 
Phonological dyslexia is rated in the following manner. Students who obtain a score greater than 90 do not have SEN; between 70 and 90 have low SEN; and lower than 70 have high SEN, requiring an extensive evaluation with a specialist.

The grading for visual dyslexia is that if the score obtained is greater than 90, the student does not have SEN; if the score is between 50 and 90, the student has low SEN and requires adjustments to their classes. However, students who obtain a score which is lower than 50 have high SEN and require an extensive evaluation with a specialist. The grading ranges are defined by previous teachers' experiences and their previous prediagnosis tests.

\subsection{Demonstration}

Helpdys research resulted in the creation of web and mobile apps. This artifact was used effectively to UX and prototype to improve the learning process of dyslexic children. The immediate contribution of this research to the learning process was implemented in the "Escuela Linea Equinoccial" school, located in a rural zone of Calacali in Quito (Ecuador). In a broader context, the artifact serves as a valuable tool in the education system.

From November 2019 to October 2020, Helpdys was used in the "Escuela Fiscal Linea Equinoccial" school to facilitate the detection of dyslexia in children from 7 to 10 years old. During this period, and due to the limited room number capability, the school performed 50 tests to identify and improve the children's progress. Additionally, teachers from the third and fourth grades used the app to detect dyslexia in their new students. The prediagnosis test must be performed twice in a school year and becomes an indicator to track children's evolution.

\subsection{Evaluation}

The current work incorporated user experience and prototyping to fulfill app requirements, resulting in an easy-to-use app. The authors assessed the apps with the Mobile App Rating Scale (MARS) tool to evaluate engagement, functionality, aesthetics, and information.

MARS [58] is a tool to evaluate web and mobile app quality. In this research, four quality subscales, which contain a total of 18 questions, were considered:

- Engagement refers to whether the app is fun, engaging, customizable, interactive, and well targeted to the audience. It includes five questions (Entertainment, Interest, Customization, Interactivity, and Target group).

- Functionality refers to whether the app is functioning, easy to learn, easy to navigate, and has flow logic and gestural design. It contains four questions (Performance, Ease of use, Navigation, and Gestural design).

- Aesthetics refers to graphic design, overall visual appeal, color scheme, and stylistic consistency. It contains three questions (Layout, Graphics, and Visual appeal).

- Information refers to high-quality data from a credible source. It has seven questions (Accuracy of app description, Goals, Information Quality, Information Quantity, Visual information, Credibility, and Evidence base). However, for this study, the last item is excluded because it contains no measurable data.

The teachers evaluated the four prototypes: low-fidelity, medium-fidelity, high-fidelity, and operational, while the children assessed the high-fidelity and operational prototypes.

To evaluate the operational prototype, the MARS tool was used, because it is simple and reliable for measuring the quality of apps by end users. Additionally, MARS was selected because it has been used in numerous studies to assess mobile app quality and has become almost a standard. In this case, the evaluations were carried out online with some teachers and children, due to the current pandemic.

The MARS evaluation tool had to be changed to adapt the questions to children from 7 to 10 years old. The complexity and the number of questions were reduced from 18 to 16 to be suitable for children. The MARS evaluation for children was conducted with the supervision of teachers and the authors of this research to overcome reading and understanding barriers. 


\section{Results}

The immediate contribution of this research to the learning process was implemented in the "Escuela Linea Equinoccial" school, located in a rural zone of Calacali in Quito (Ecuador). In a broader context, the artifact serves as a valuable tool in the education system. This zone has a population of approximately 7800 inhabitants. The school has 17 teachers who work from 7:00 am to 4:00 pm from Monday to Friday. There are 14 classrooms that accommodate 398 students, including 25 children with SEN. They have only one computer center classroom for the whole school. Inside the classroom, there are a total of 14 computers, 7 of them working properly.

The students come from low-income families, with permanent or temporary jobs focused on agriculture, floriculture, handicrafts, and general services. Interaction in the community is relatively harmonious. However, communication between students is severely affected by bullying students, which causes violent physical and psychological acts. Additionally, it was observed that the student population constantly varied due to school dropouts during the year. This is caused by temporary foreign refugees, irregular residency, and migration to other cities. In this school, teachers noticed that the learning process had become more complicated for some children, resulting in stress and disorientation and a setback in their learning processes. This is where technology plays an important role in meeting dyslexic students' needs; the developers worked with teachers to validate functional requirements and application contents.

To evaluate the high-fidelity prototype, the MARS tool was used [58]; the evaluation was performed by a group of 15 teachers [25] and 25 children. Each MARS item used a five-point scale, with the following meaning: 1-Inadequate, 2-Poor, 3-Acceptable, 4-Good, and 5-Excellent.

The MARS evaluation was performed in two ways. The first was the web app assessed by children, and the second was the web and mobile apps tested by teachers. It is important to mention that the evaluation of the mobile application by the children could not be carried out due to a lack of mobile devices. Figure 7 shows the calculations of category averages for the web app as scored by the children. Evaluation of the web version resulted in an overall average on the MARS scale of $4.72(\mathrm{SD}=0.50)$ out of 5 . All subscales show a score higher than 4 out of 5, demonstrating the quality of the apps as perceived by the children, also indicating the app's ease of use.

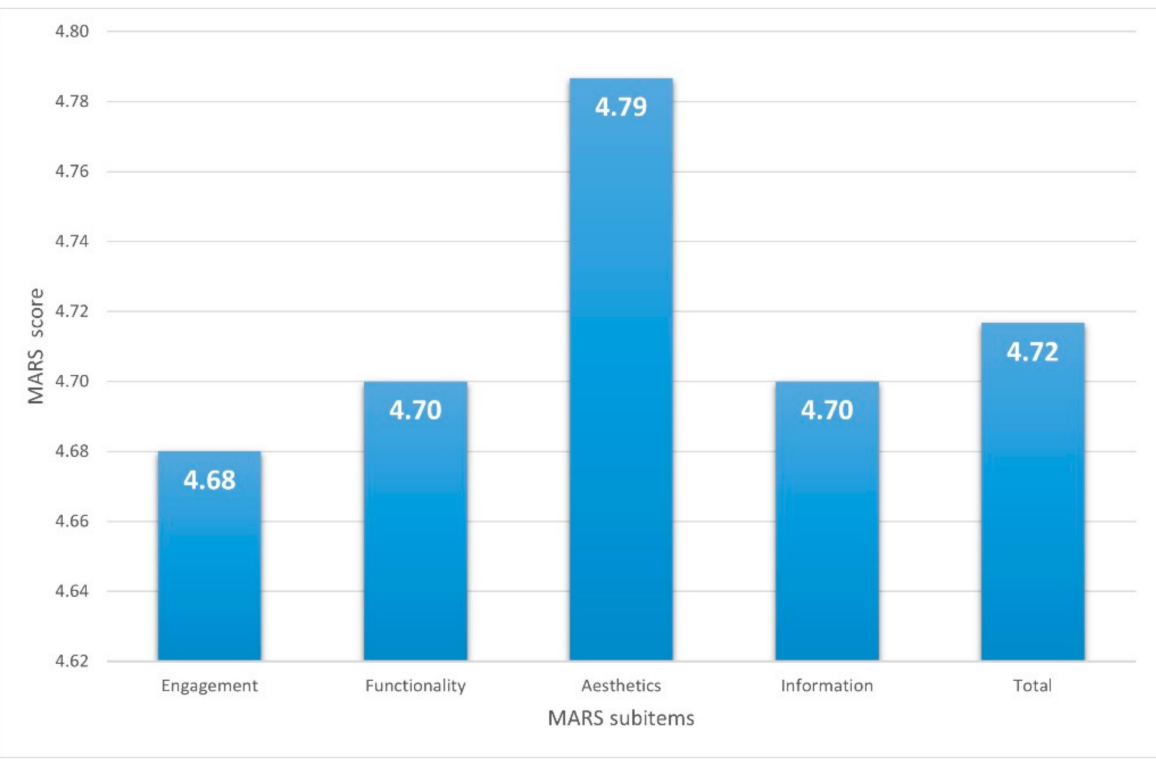

Figure 7. MARS web results for children using the high-fidelity prototype.

Figure 8 shows the evaluation of the quality of the high-fidelity web prototype by the teachers. This evaluation resulted in an overall average of $4.31(\mathrm{SD}=0.67)$ out of 5 . 
The teachers found the app was user friendly and appreciated the design and the game's functionality. The categories "entertaining" and "would you pay for this app?" got a score lower than four due to the status of low-income families.

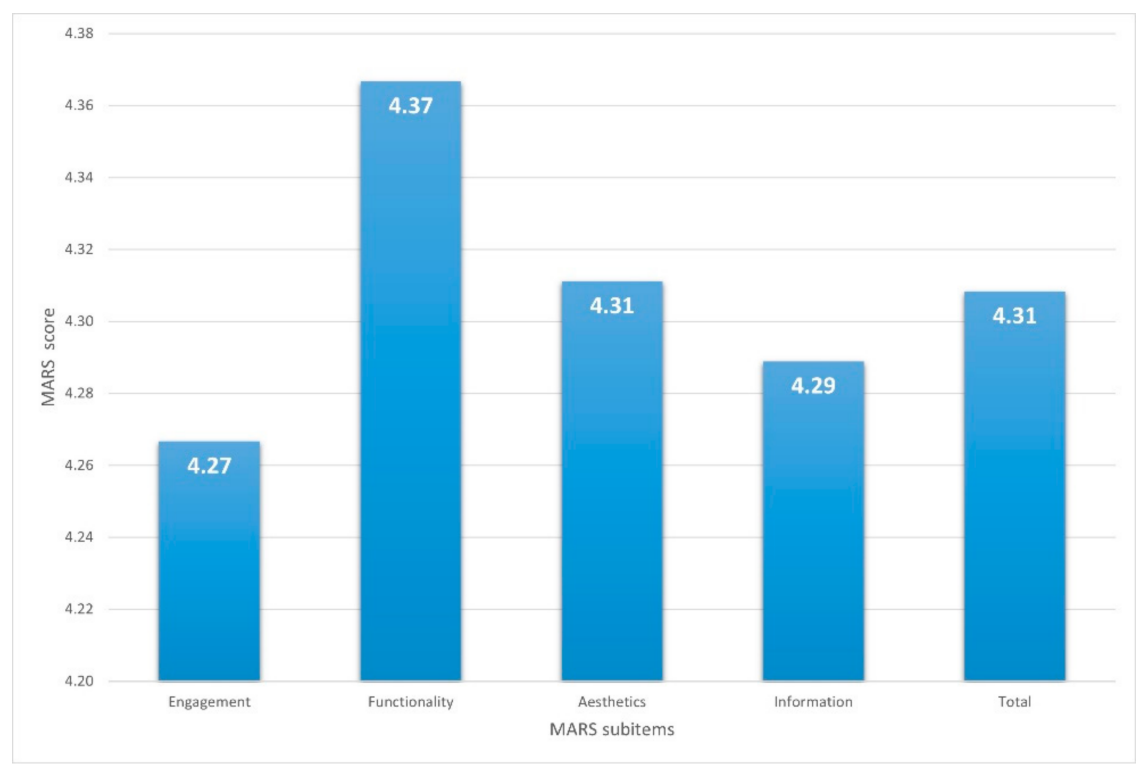

Figure 8. MARS web results of teachers using the high-fidelity prototype.

Figure 9 shows the evaluation of the quality of the high-fidelity mobile prototype by the teachers. An overall result of $4.21(\mathrm{SD}=0.68)$ out of 5.0 was obtained. The teachers found the app enjoyable to work with, especially the design. The visual appeal, quality of information, and affordability of the app scored a grade lower than 4.0, which shows that the app's content needs to be improved.

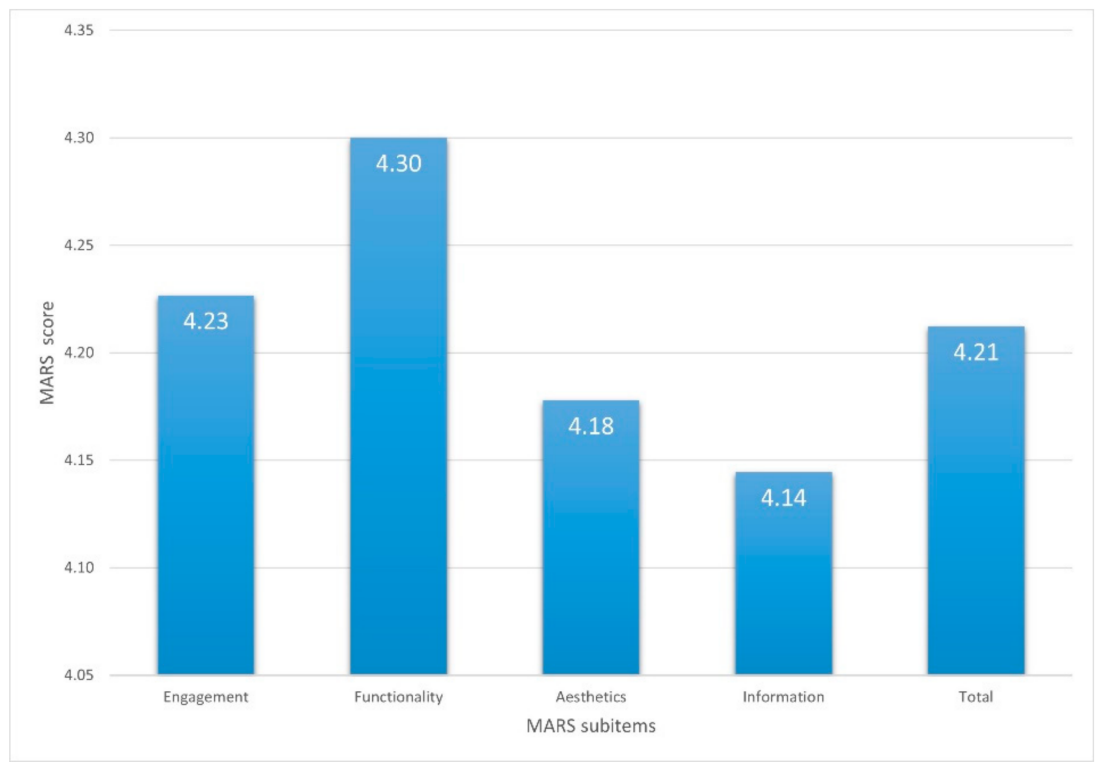

Figure 9. MARS mobile results of teachers using high-fidelity prototype.

The results of the evaluation of the operational prototype by the teachers showed that the overall quality of the application varied between 4.85 , the lowest, and 4.93 , the highest. On average, the app obtained an overall score of 4.89. The sections with the highest evaluations were: Engagement (average $=4.88)$, Aesthetics (average $=4.93)$, and Information (average $=4.90$ ); Functionality (average $=4.85$ ) was the lowest. With a result 
of 4.89 out of 5.0 MARS score (SD = 0.32), the operational prototype, compared with the high-fidelity prototype, shows a substantial improvement. This is shown in Figure 10.

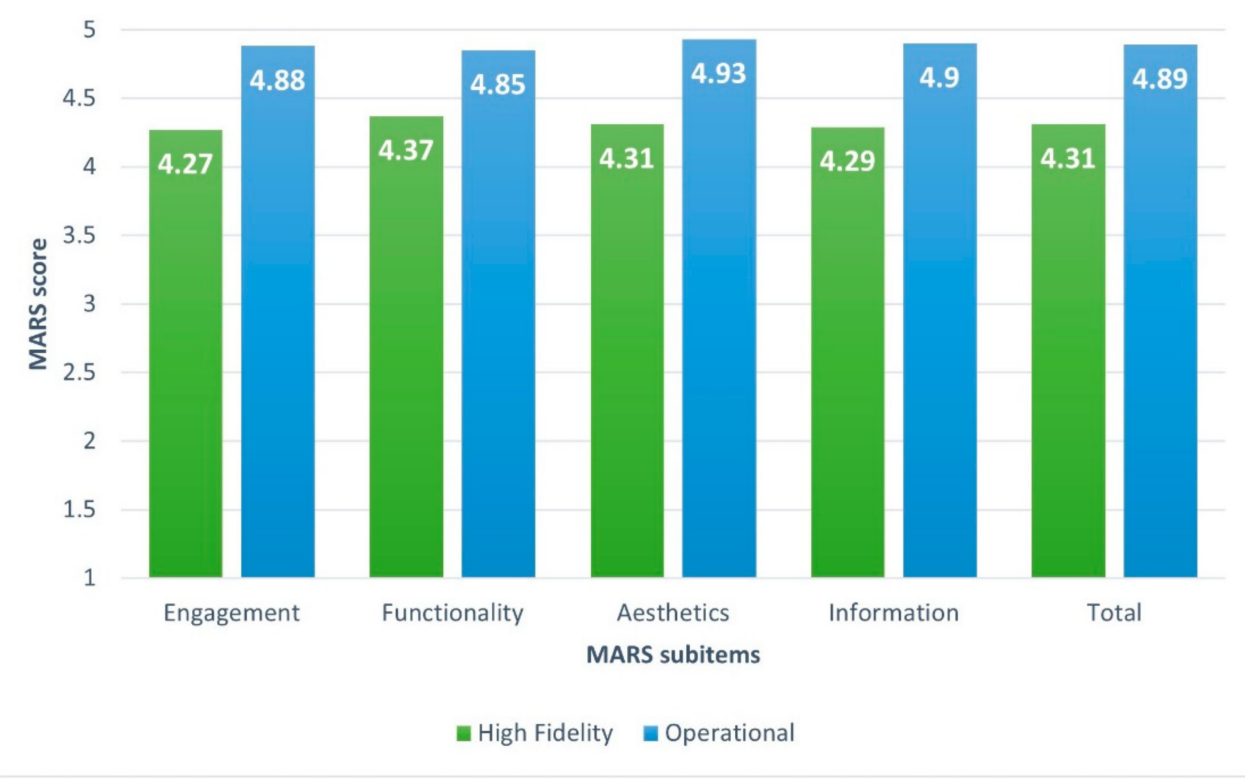

Figure 10. MARS results of teachers using operational prototype.

\section{Children Pre-Diagnosis Evaluations}

Table 2 shows the results obtained from the prediagnosis tests at the beginning of the app operation. This table depicts the more relevant cases.

Table 2. Results of phonological and visual dyslexia initial tests on children from 7 to 10 years old (November 2019).

\begin{tabular}{ccccccc}
\hline \multirow{2}{*}{ Number } & \multirow{2}{*}{ Age } & $\begin{array}{c}\text { Grade } \\
\text { Level }\end{array}$ & \multicolumn{2}{c}{ Phonological Dyslexia } & \multicolumn{2}{c}{ Visual Dyslexia } \\
\cline { 4 - 6 } & & 3 & Points & Diagnostic & Points & Diagnostic \\
\hline Student 1 & 7 & 55 & High SEN & 72 & Low SEN \\
Student 2 & 7 & 3 & 50 & High SEN & 36 & High SEN \\
Student 3 & 8 & 3 & 65 & High SEN & 84 & Low SEN \\
Student 4 & 8 & 3 & 50 & High SEN & 68 & Low SEN \\
Student 5 & 8 & 3 & 45 & High SEN & 38 & Low SEN \\
Student 6 & 9 & 4 & 35 & High SEN & 52 & Low SEN \\
Student 7 & 10 & 4 & 20 & High SEN & 36 & High SEN \\
\hline
\end{tabular}

Table 3 shows the results obtained from the prediagnosis test at the end of the school year 2019-2020, after having applied the changes to Helpdys suggested by the teachers during the academic year.

Table 3. Results of phonological and visual dyslexia initial tests on children from 8 to 10 years old (July 2020).

\begin{tabular}{lcccccc}
\hline \multirow{2}{*}{ Number } & \multirow{2}{*}{ Age } & \multirow{2}{*}{$\begin{array}{c}\text { Grade } \\
\text { Level }\end{array}$} & \multicolumn{2}{c}{ Phonological Dyslexia } & \multicolumn{2}{c}{ Visual Dyslexia } \\
\cline { 4 - 7 } & & 3 & Points & Diagnostic & Points & Diagnostic \\
\hline Student 1 & 8 & 65 & High SEN & 84 & Low SEN \\
Student 2 & 8 & 3 & 70 & High SEN & 100 & None \\
Student 3 & 8 & 3 & 50 & High SEN & 52 & Low SEN \\
Student 4 & 9 & 3 & 50 & High SEN & 84 & None \\
Student 5 & 9 & 3 & 60 & High SEN & 84 & None \\
Student 6 & 9 & 4 & 55 & High SEN & 52 & Low SEN \\
Student 7 & 10 & 4 & 60 & High SEN & 52 & High SEN \\
\hline
\end{tabular}




\section{Discussion}

Teachers from rural zones in Calacali, Ecuador, have difficulties in identifying and following up on conditions related to dyslexia. Before the current research, teachers used to use manual tests that are not entirely effective and take too much time to evaluate and rate. Furthermore, teachers do not have records of past evaluations to track children's development. Having teachers involved from the start of the app development was significant due to their hard work to make it happen. The teachers' engagement contributed to improving the app features-being part of it encouraged them to treat the project as their own. With Helpdys, teachers have overcome problems that they faced previously.

The COVID-19 pandemic has affected the educational system in Ecuador. The inequality between social classes due to the lack of tech tools and the digital divide of urban and rural zones has become a serious problem [59,60]. Calacali, which is in a rural zone, was selected to study the problem mentioned above. Teachers there have made a remarkable effort to prevent school dropouts. The economic situation has severely impacted many families, making it virtually impossible for them to access tech resources. Some families can only afford one mobile device, which is shared by two or more children. In addition, most parents are unable to supervise their children's schoolwork due to their lack of technical skills. As the school provides Internet access in the computer center classroom, the role of teachers has become vital in addressing this problem.

RQ1. Helpdys is a web and mobile app that treats dyslexia, especially in children from 7 to 10 years old; the results suggest that Helpdys can be a successful companion app for children with several conditions related to dyslexia.

Tables 2 and 3 show that many students increase their scores, keeping in mind that the phonologic dyslexia test is graded out of five points, and the visual dyslexia test out of 16 points. Student 2 is a remarkable case, showing an extraordinary improvement in their scoring. This improvement was due to the parents' interest and the teacher's determination to help the child.

RQ2. The correct way to develop a web and mobile app is with the direct participation of the stakeholder, the children, teachers, and authorities. As they felt part of it, the children took great care to contribute to the app's improvement. The teachers saw in the app an opportunity to help children concretely using the ICT. Finally, authorities contributed the teachers' schedules and the app development team's facilities.

RQ3. The MARS tool was used to guarantee acceptance of apps by end users and was applied to all the prototypes developed. The low-fidelity prototype allowed for improving the understanding of the site's navigability and clarifying any doubts. In the beginning, the teachers did not understand this prototype's purpose and the images that represent the interfaces. Doubts and comments were satisfactorily answered, and the feedback was considered for the next prototypes. During the medium-fidelity prototype evaluation, the teachers demonstrated a quick understanding of the app's functionality and navigability. The children were able to navigate with ease, and they liked the games and the images. Evaluating the high-fidelity prototype, entertainment, navigation, graphics, and visual information obtained the lowest scores, which indicated that the app needed to improve these factors in the next iteration. Finally, the results show that the app was improved in all aspects of the operational prototype. All the MARS assessment category scores were higher compared with the previous prototypes, reaching top scores in some categories. The results obtained indicate the app's quality and ease of use.

\section{Conclusions}

Mobile devices are widely used, including in rural communities, providing a promising tool for providing structural solutions for supporting children with special needs. A single intervention for each child is very time- and resource-consuming; therefore, using an app as supplementary to a therapist's treatment can be a great help. 
The teachers involved in the app's design and evaluation were motivated because it is a beneficial technological resource for their classes. Their help at the moment of the prototype's design allowed them to have a high-quality final product.

In March 2020, schools in Ecuador were closed because of the COVID-19 pandemic; lockdown drastically changed the educational process [61]. Therefore, web and mobile apps were fundamental tools for giving continuity to the teaching-learning process.

The apps improved the learning processes of children with dyslexia through games with easy-to-use tools. The children helped to evaluate the app, and several children demonstrated significant improvements regarding their dyslexia due to their involvement.

The improvement of Helpdys in its aesthetic qualities, usability, and accessibility resulted from using the colors blue, black, and white; these colors are recommended in web accessibility for people with dyslexia. The fonts chosen were sans serif and Helvetica Neue; the fonts are simple and suitable for working with people with dyslexia.

One of the advantages of the MARS tool is its capacity to be flexible and adaptable. The current work uses the original model for teacher evaluations and a simplified one for children to improve understandability. The MARS evaluation results show that the apps have a high-quality level, and all the students' and teachers' suggestions were applied to improve the final version. As future work, the next step is designing an app for dyscalculia to complement the current work, thus providing a more comprehensive system for the future.

Author Contributions: Conceptualization, A.L.; methodology, A.L.; software, J.C. and N.C.; validation, J.C. and N.C.; formal analysis, A.L. and C.Y.; investigation, A.L.; writing-original draft preparation, A.L., J.C., and N.C.; writing-review and editing, A.L., C.Y., and S.L.-M.; supervision, S.L.-M. All authors have read and agreed to the published version of the manuscript.

Funding: This work was supported by the EduTech project (609785-EPP-1-2019-1-ES-EPPKA2CBHEJP) co-funded by the Erasmus+ Programme of the European Union.

Institutional Review Board Statement: Not applicable.

Informed Consent Statement: Not applicable.

Data Availability Statement: Not applicable.

Acknowledgments: To the authorities, teachers, and psychologists of the school "Escuela Fiscal Linea Equinoccial" (Ecuador), their help was vital to developing the current work.

Conflicts of Interest: The authors declare no conflict of interest.

\section{References}

1. Frederickson, N.; Cline, T. Special Educational Needs, Inclusion, and Diversity: A Textbook; Open University Press: London, UK, 2002; ISBN 978-0-335-20973-6.

2. Warnock, M. Special educational needs: A new look. In Challenges for Inclusion; Brill: Leiden, The Netherlands, 2008; pp. 43-65.

3. Tsakalaki, A.; Tissot, C. Schools Are Failing Pupils with Special Needs, Despite Best Efforts of Dedicated Staff. Available online: http:/ / theconversation.com/schools-are-failing-pupils-with-special-needs-despite-best-efforts-of-dedicated-staff-12 3400 (accessed on 23 April 2021).

4. National Audit Office. Support for Pupils with Special Educational Needs and Disabilities in England; NAO: London, UK, 2019; p. 60.

5. Cramer, S. Dyslexia International: Better Training, Better Teaching; Dyslexia International: Brussels, Belgium, 2014.

6. Meegan, S.; MacPhail, A. Irish physical educators' attitude toward teaching students with special educational needs. Eur. Phys. Educ. Rev. 2006, 12, 75-97. [CrossRef]

7. American Psychiatric Association. DSM-5 Neurodevelopmental Disorders. In Diagnostic and Statistical Manual of Mental Disorders; American Psychiatric Association: Washington, DC, USA, 2013.

8. International Dyslexia Association. DSM-5 Changes in Diagnostic Criteria for Specific Learning Disabilities (SLD)1: What Are the Implications? Available online: https://dyslexiaida.org/dsm-5-changes-in-diagnostic-criteria-for-specific-learning-disabilitiessld1-what-are-the-implications / (accessed on 8 February 2021).

9. International Dyslexia Association Definition of Dyslexia. Available online: https://dyslexiaida.org/definition-of-dyslexia/ (accessed on 18 March 2021).

10. Norton, E.S.; Beach, S.D.; DE Gabrieli, J. Neurobiology of dyslexia. Curr. Opin. Neurobiol. 2015, 30, 73-78. [CrossRef] [PubMed] 
11. Kohli, A.; Sharma, S.; Padhy, S.K. Specific learning disabilities: Issues that remain unanswered. Indian J. Psychol. Med. 2018, 40, 399-405. [CrossRef] [PubMed]

12. Mather, N.; White, J.; Youman, M. Dyslexia around the world: A snapshot. Learn. Disabil. 2020, 25, 17. [CrossRef]

13. Méndez, R.; Carrera, J. Investigación y Planificación para el Diseño de un Aula de Apoyo Psicopedagógico y Aporte de la Misma al Desarrollo y Seguridad de la Educación de Niños con Dificultades de Aprendizaje. Master's Thesis, Instituto de Altos Estudios Nacionales, Quito, Ecuador, 2003; p. 118.

14. Vélez Calvo, X.; Tárraga Mínguez, R.; Fernández Andrés, M.I.; Sanz-Cervera, P.; Blázquez-Garcés, J.V.; Tijeras Iborra, A. Incidencia de la dislexia en Ecuador: Relación con el CI, lateralidad, sexo y tipo de escuela. Rev. INFAD Psicol. 2016, 2, 249. [CrossRef]

15. Morris, M.R.; Fourney, A.; Ali, A.; Vonessen, L. Understanding the needs of searchers with dyslexia. In Proceedings of the 2018 CHI Conference on Human Factors in Computing Systems, ACM, Montreal, QC, Canada, 21-26 April 2018; pp. 1-12.

16. McCardle, P.; Scarborough, H.S.; Catts, H.W. Predicting, explaining, and preventing children's reading difficulties. Learn. Disabil. Res. Pract. 2001, 16, 230-239. [CrossRef]

17. Reid, G.; Strnadová, I.; Cumming, T. Expanding horizons for students with dyslexia in the 21st century: Universal design and mobile technology. J. Res. Speéc. Educ. Needs 2013, 13, 175-181. [CrossRef]

18. Snowling, M.J.; Hulme, C.; Nation, K. Defining and understanding dyslexia: Past, present and future. Oxf. Rev. Educ. 2020, 46, 501-513. [CrossRef]

19. Australian Dyslexia Association. Dyslexia, Dysgraphia and Dyscalculia? Available online: https://dyslexiaassociation.org.au/ support/dyslexiadysgraphia-and-dyscalculia/ (accessed on 14 March 2021).

20. Catts, H.; Kamhi, A. The connections between language and reading disabilities. First Lang. 2006, 26, 339-342. [CrossRef]

21. International Dyslexia Association. Understanding Dysgraphia. Available online: https://dyslexiaida.org/understandingdysgraphia/ (accessed on 14 February 2021).

22. INSERM Collective Expertise Centre. Dyslexia Dysorthography Dyscalculia: Review of the scientific data. In INSERM Collective Expert Reports; INSERM: Paris, France, 2000.

23. The Dyslexia Association. What Is Dyscalculia? Available online: https:/ / www.dyslexia.uk.net/specific-learning-difficulties/ dyscalculia/ (accessed on 14 March 2021).

24. California Department of Education. California Dyslexia Guidelines; CDE Press: Sacramento, CA, USA, 2017.

25. Snowling, M.; Gooch, D.; Henderson, L. Dyslexia. In Encyclopedia of Human Behavior; Elsevier: Amsterdam, The Netherlands, 2012; pp. 732-739.

26. Morken, F.; Jones, L.; Helland, W. Disorders of language and literacy in the prison population: A scoping review. Educ. Sci. 2021, 11, 77. [CrossRef]

27. Hodgson, S.; Addington, L.; Smith, H. The Human Cost of Dyslexia: The Emotional and Psychological Impact of Poorly Supported Dyslexia; British Dyslexia Association. 2019. Available online: https://www.bdadyslexia.org.uk/about/all-partyparliamentary-group-dyslexia-and-spld-appg (accessed on 21 April 2021).

28. WHO. Disability and Health. 2018. Available online: https://www.who.int/news-room/fact-sheets/detail/disability-and-health (accessed on 17 January 2021).

29. Gething, L. Sources of double disadvantage for people with disabilities living in remote and rural areas of New South Wales, Australia. Disabil. Soc. 1997, 12, 513-531. [CrossRef]

30. Why I Celebrate Technology as a Go-To for Kids with Dyslexia. Available online: https:/ /www.understood.org/en/communityevents/blogs / expert-corner/2015/10/23/why-i-celebrate-technology-as-a-go-to-for-kids-with-dyslexia (accessed on 14 February 2021).

31. Șerban, A.; Stefan, V.; Potocnik, D.; Moxon, D.; Pasic, L. Social Inclusion, Digitalisation and Young People. Research Study; EU-Council of Europe Youth Partnership; Council of Europe and European Commission: Strasbourg, France, 2020; p. 95.

32. Ojanen, E.; Jere-Folotiya, J.; Yalukanda, C.; Sampa, F.; Nshimbi, C.; Katongo, M.; Choopa, M.; Lyytinen, H. Mobile solution for better reading instruction in Rural Africa. In Proceedings of the 2015 IST-Africa Conference, Lilongwe, Malawi, 6-8 May 2015; pp. 1-13.

33. Patel, P.; Torppa, M.; Aro, M.; Richardson, U.; Lyytinen, H. GraphoLearn India: The effectiveness of a computer-assisted reading intervention in supporting struggling readers of english. Front. Psychol. 2018, 9, 1045. [CrossRef]

34. Ronimus, M.; Eklund, K.; Pesu, L.; Lyytinen, H. Supporting struggling readers with digital game-based learning. Educ. Technol. Res. Dev. 2019, 67, 639-663. [CrossRef]

35. Stroustrup, B. Programming: Principles and Practice Using C++, 2nd ed.; Addison-Wesley: Upper Saddle River, NJ, USA, 2014; ISBN 978-0-321-99278-9.

36. Calero, C.; Piattini, M. Puzzling out software sustainability. Sustain. Comput. Inform. Syst. 2017, 16, 117-124. [CrossRef]

37. Penzenstadler, B.; Raturi, A.; Richardson, D.; Calero, C.; Femmer, H.; Franch, X. Systematic mapping study on software engineering for sustainability (SE4S). In Proceedings of the 18th International Conference on Evaluation and Assessment in Software Engineering-EASE '14; ACM Press: London, UK, 2014; pp. 1-14.

38. Statista Internet Users in the World. 2020. Available online: https:/ /www.statista.com/statistics/617136/digital-populationworldwide/ (accessed on 29 November 2020).

39. Montiel, I.; Delgado-Ceballos, J.; Ortiz-De-Mandojana, N.; Antolin-Lopez, R. New ways of teaching: Using technology and mobile apps to educate on societal grand challenges. J. Bus. Ethic 2019, 161, 243-251. [CrossRef] 
40. Hevner, A.; March, S.; Park, J.; Ram, S. Design science in information systems research. MIS Q. 2004, 28, 75. [CrossRef]

41. Pedersen, R.; Clemmensen, T. A design science approach to interactive greenhouse climate control using lego mindstorms for sensor-intensive prototyping. In Human Work Interaction Design. Work Analysis and HCI; Campos, P., Clemmensen, T., Nocera, J.A., Katre, D., Lopes, A., Ørngreen, R., Eds.; IFIP Advances in Information and Communication Technology; Springer: Berlin/Heidelberg, Germany, 2013; Volume 407, pp. 73-89, ISBN 978-3-642-41144-1.

42. Montenegro, C.; Murillo, M.; Gallegos, F.; Albuja, J. DSR approach to assessment and reduction of information security risk in TELCO. IEEE Lat. Am. Trans. 2016, 14, 2402-2410. [CrossRef]

43. Peffers, K.; Tuunanen, T.; Rothenberger, M.A.; Chatterjee, S. A design science research methodology for information systems research. J. Manag. Inf. Syst. 2007, 24, 45-77. [CrossRef]

44. Rumberger, R.; Lim, S. Why Students Drop Out of School: A Review of 25 Years of Research; California Dropout Research Project, Report \#15. October 2008, pp. 1-130. Available online: http:/ /cdrpsb.org/pubs_reports.htm (accessed on 21 April 2021).

45. Gaggi, O.; Galiazzo, G.; Palazzi, C.; Facoetti, A.; Franceschini, S. A serious game for predicting the risk of developmental dyslexia in pre-readers children. In Proceedings of the 21st International Conference on Computer Communications and Networks (ICCCN), Munich, Germany, 30 July-2 August 2012; pp. 1-5.

46. Holz, H.; Beuttler, B.; Ninaus, M. Design rationales of a mobile game-based intervention for German dyslexic children. In Proceedings of the 2018 Annual Symposium on Computer-Human Interaction in Play Companion Extended Abstracts, Melbourne, VIC, Australia, 28-31 October 2018; pp. 205-219.

47. Boehm, B. A spiral model of software development and enhancement. IEEE Comput. 1988, 21, 62-72. [CrossRef]

48. Kristiadi, D.P.; Udjaja, Y.; Supangat, B.; Prameswara, R.Y.; Warnars, H.L.H.S.; Heryadi, Y.; Kusakunniran, W. The effect of UI, UX and GX on video games. In Proceedings of the 2017 IEEE International Conference on Cybernetics and Computational Intelligence (CyberneticsCom), Phuket, Thailand, 20-22 November 2017; pp. 158-163.

49. Beregovyi, O. The Difference between UI and UX Design; IV All-Ukrainian Scientific and Practical Conference "Innovative tendencies in the preparation of faculties in the intellectual and multilingual globalized world". 2019, pp. 61-63. Available online: https: / / er.knutd.edu.ua/handle/123456789/13036 (accessed on 21 April 2021).

50. Garrett, J. The Elements of User Experience: User-Centered Design for the Web and Beyond, 2nd ed.; New Riders: Berkeley, CA, USA, 2011; ISBN 978-0-321-68368-7.

51. Hursch, W.; Lopes, C. Separation of Concerns; Technical Report NU-CCS-95-03; Northeastern University: Boston, MA, USA, 1995.

52. W3C Recommendation. Web Content Accessibility Guidelines (WCAG) 2.1. Available online: https://www.w3.org/TR/WCAG2 1/ (accessed on 14 March 2021).

53. Bradford, J. Dyslexia Parents Resource: Dyslexia Symptoms, Dyslexia Treatment, Dyslexia Help. Available online: https: / / essaypro.com/dyslexia-parent-com (accessed on 13 January 2021).

54. Rello, L.; Bigham, J. Good background colors for readers: A study of people with and without dyslexia. In Proceedings of the 19th International ACM SIGACCESS Conference on Computers and Accessibility, ACM, Baltimore, MD, USA, 29 October-1 November 2017; pp. 72-80.

55. Sanchez-Gordon, S.; Luján-Mora, S. How could MOOCs become accessible? The case of EdX and the future of inclusive online learning. J. Univ. Comput. Sci. 2016, 22, 55-81.

56. Rello, L.; Baeza-Yates, R. Evaluation of DysWebxia: A reading app designed for people with dyslexia. In Proceedings of the 11th Web for All Conference; Association for Computing Machinery: New York, NY, USA, 2014.

57. Tests for Dyslexia and Language Disorders. Available online: http://dyslexiahelp.umich.edu/professionals/learn-aboutdyslexia/diagnosing-dyslexia/tests (accessed on 13 January 2021).

58. Stoyanov, S.; Hides, L.; Kavanagh, D.; Zelenko, O.; Tjondronegoro, D.; Mani, M. Mobile Application Rating Scale (MARS). JMIR mHealth uHealth 2015, 3, e27.

59. Esteban-Navarro, M.-Á.; García-Madurga, M.-Á.; Morte-Nadal, T.; Nogales-Bocio, A.-I. The rural digital divide in the face of the COVID-19 pandemic in Europe-Recommendations from a scoping review. Informatics 2020, 7, 54. [CrossRef]

60. Ye, L.; Yang, H. From digital divide to social inclusion: A tale of mobile platform empowerment in rural areas. Sustainability 2020, 12, 2424. [CrossRef]

61. Moreno, L. Decreto Presidencial No. 1017; Ministerio de Defensa Nacional: Bogotá, Colombia, 2020. 